\title{
FEA-based optimisation of a clinching process with an open multiple-part die aimed at damage minimisation in CR240BH-AISi10MnMg joints
}

Bernd-Arno Behrens, Anas Bouguecha, Milan Vucetic, Sven Hübner, Deniz Yilkiran, YiLin Jin, and Ilya Peshekhodov ${ }^{\mathrm{a}}$

Institute of Forming Technology and Machines (IFUM), Leibniz Universität Hannover, An der Universität 2, 30823 Garbsen, Germany

\begin{abstract}
The paper presents results of a FEA-based tool design optimisation for a clinching process with an open multiple-part die. The studied materials are the bakehardening steel CR240BH $(1.5 \mathrm{~mm})$ on the punch side and the die-cast aluminium alloy AlSi10MnMg $(2.95 \mathrm{~mm})$ on the die side. The objective of the optimisation was to minimise probability of cracks that appear at the outer circumference of the bottom of the clinch joint in AlSi10MnMg. In the framework of the optimisation, it was possible to minimise crack probability by varying geometrical parameters of the tools though at the cost of slightly worse but still tolerable geometrical parameters of the clinch joint.
\end{abstract}

\section{Introduction}

The joining method clinching has been used in the automotive manufacturing since a decade because of its efficiency, cleanliness and low noise. According to the standard DIN 8593, the mechanical joining processes are listed under the group "joining by forming" [1]. These are divided in processes

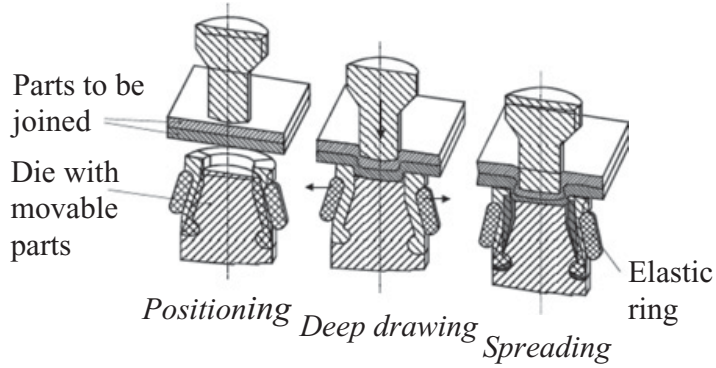

Figure 1. Step sequence of a clinching process with an open multiple-part die without a cutting component according to [2]. with and without auxiliary joining elements. Clinching involves the joining methods by local forming and does not require an extra fastener.

During clinching, two materials are formed to be joined into a die by a punch. A button is formed on the die side of the sheets and an interlock is formed between the sheets. Clinching has partially replaced thermal joining processes. In addition, clinching has a great potential for weight minimisation of the joining components and also economic benefits. It is principally possible for multiple-part joining partners with different material and sheet thicknesses, e.g. for steel and aluminium [3, 4].

${ }^{a}$ Corresponding author: peshekhodov@ifum.uni-hannover.de 

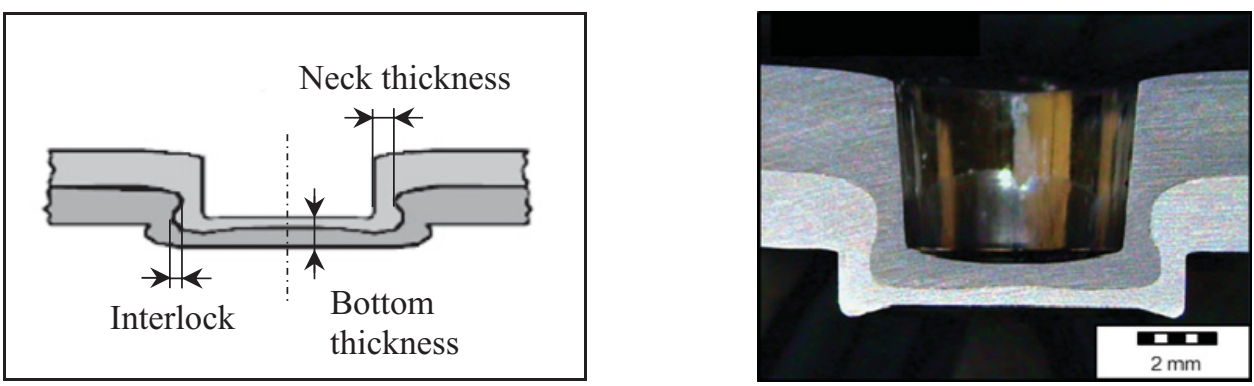

Figure 2. Geometrical parameters and cross section of a clinching circular point without cutting component.

In the sheet metal forming industry two modes of clinching without cutting component are widely used. These are clinching tools with a closed single-part die and with an open multiple-part die. The material flows similarly on the punch side for both variants while they are especially different on the die side. The present paper deals with the clinching with an open multiple-part die without a cutting component. The process sequence of the clinching with an open multiple-part die is illustrated in Fig. 1. As Fig. 1 depicts the process is mainly divided in three steps, positioning, deep drawing and spreading.

A formed clinching circular point without cutting component is illustrated on the right side of Fig. 2. On the left side the geometrical parameters of the clinching circular point are shown, like neck thickness $t_{\mathrm{n}}$, interlock $f$ and bottom thickness $t_{\mathrm{b}}$. The geometrical parameter of a clinching joint is affected by many factors related to the clinching process, for example, the anvil depth and width of the die and the radius of the punch tip. The quality of a clinching joint can be measured by static and fatigue strength or visual appearance of the joint. The assessment of the joint strength is usually defined as the parameter neck-thickness, interlock and the bottom-thickness. The required neck-thickness and interlock need to satisfy the joint strength. There are three basic modes of failure of the clinching joint when a joint is loaded: neck fractures, button separations and mixed modes (neck fracture + button separation). In the three failure modes, the mixed failure mode is regarded as the ideal failure mode, which is with a good relationship of joint parameters between the interlock $f$ and neck thickness $t_{\mathrm{n}}$ [5].

Cracks occurs in the area of the outer circumference of the die-cast aluminium alloy sheet AlSi10MnMg on the side of the die from the sample with an open multiple-part die, as illustrated in Fig. 3. During the clinching process, high plastic strains and unfavourable tensile stresses in the die-cast aluminium are responsible for the crack appearance.

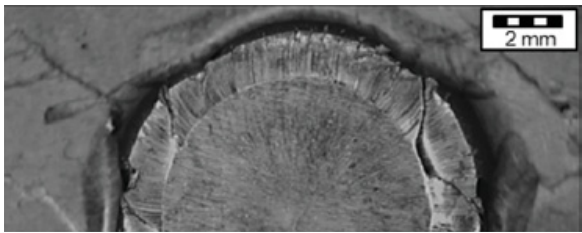

Figure 3. Circumference fractures in die cast aluminium AlSi10MnMg (2.95 mm) clinched with the bake hardening steel CR240BH $(1.5 \mathrm{~mm})$ with an open multiple-part die (joint bottom view).

The potential solution approach is to process the material sheets under compressive stress during the forming process of the joining partner. It is known that the compressive stress in the forming process can cause the material aluminium to increase the ductility at room temperature. In addition, a stepped punch is developed to improve the joining strength and the joining range. The sheet material at the punch side is moved in the interlock area and the fracture risk in the sheet material decreases with the use of a stepped punch. So the clinching tools that enhance the compressive stress during the forming process could

This is an Open Access article distributed under the terms of the Creative Commons Attribution License 4.0, which permits unrestricted use, distribution, and reproduction in any medium, provided the original work is properly cited. 



Figure 4. Stress-strain diagrams obtained in the multi-layer compression test for CR240BH (left) and AlSi10MnMg (right) [6].


Figure 5. Exp. hardening curves and their extrapolations for CR240BH (left) and AlSi10MnMg (right) [6].

be applied to realise a clinching process with die-cast aluminium alloys.

\section{Investigated materials}

Two materials were investigated in the present study. The bake-hardening steel CR240BH with a sheet thickness of $1.5 \mathrm{~mm}$ on the punch side and the die-cast aluminium alloy AlSi10MnMg with a sheet thickness of $2.95 \mathrm{~mm}$ on the die side.

To characterise the plastic flow of the investigated materials, multi-layer compression tests were carried out by using a compression modus of the quench and deformation dilatometer DIL $805 \mathrm{~A} / \mathrm{D}+\mathrm{T}$ from BÄHR Thermoanalyse GmbH. During the compression tests compressive loads up to $20 \mathrm{kN}$ were applied to the specimens. The specimen heights of the investigated materials were approximately $6 \mathrm{~mm}$ and the diameters were $5 \mathrm{~mm}$ in accordance with the cylinder compression test described in the standard DIN 50106 "Testing of metallic materials - compression test". The diameter-to-height ratios of the two sheet metals are both 5:6. The specimen of the die-cast aluminium AlSi10MnMg is comprised of two layers while the specimen of the steel material CR240BH contains four layers. The compression tests results in form of stress-strain diagrams are shown in Fig. 4. Three experimental curves are illustrated 


\section{MATEC Web of Conferences}

Table 1. Variation of the die blade stiffness $\mathrm{k}$ based on the initial blade stiffness.

\begin{tabular}{|c|c|c|c|c|c|}
\hline Parameter & I-0 & II-0 & III-0 & IV-0 & V-0 \\
\hline$k / k^{\text {ini }}[-]$ & 1 & 5 & 10 & 50 & 100 \\
\hline
\end{tabular}

Table 2. Variation of the step punch diameter $\mathrm{D}_{\mathrm{s}}$ based on the variant I-0 and III- 0 from Table 1 .

\begin{tabular}{|c|c|c|c|c|c|c|c|c|c|c|}
\hline Parameter & I-1 & I-2 & I-3 & I-4 & I-5 & III-1 & III-2 & III-3 & III-4 & III-5 \\
\hline$D_{\mathrm{S}} / D_{\mathrm{s}}^{\text {ini }}[-]$ & 0.96 & 0.98 & 1.00 & 1.02 & 1.04 & 0.96 & 0.98 & 1.00 & 1.02 & 1.04 \\
\hline
\end{tabular}

Table 3. Variation of the step punch diameter $\mathrm{D}_{\mathrm{s}}$ based on the variant $\mathrm{V}-0$ from Table 1 .

\begin{tabular}{|c|c|c|c|c|c|}
\hline Parameter & $\mathbf{V - 1}$ & $\mathbf{V - 2}$ & $\mathbf{V - 3}$ & $\mathbf{V - 4}$ & $\mathbf{V - 5}$ \\
\hline$D_{\mathrm{s}} / D_{\mathrm{s}}^{\text {ini }}[-]$ & 0.96 & 0.98 & 1.00 & 1.02 & 1.04 \\
\hline
\end{tabular}

along with pictures of the specimens at the end of the test. Furthermore Fig. 4 depicts an indication of the data range used for the flow curve determination. The hardening curves from the results of the multi-layer compression tests are presented in Fig. 5. The extrapolated of the hardening curves were conducted according to the model of Gosh (CR240BH) and the model of Hocket and Sherby (AlSi10MnMg) [6].

The fracture initiation behaviour of the die-cast aluminium alloy was modelled with the Oyane criterion in the form of its implementation in the program Simufact.forming:

$$
C=\int_{0}^{\bar{\varepsilon}_{p l}}\left(\frac{\sigma_{\mathrm{m}}}{\bar{\sigma}}+B\right) d \bar{\varepsilon}_{p l} \geq C_{\text {crit }} .
$$

In Oyane damage criterion the coefficient value B of the investigated aluminium alloy in this study can be determined equal to 2.36 according to the literature reference [6], in which the material aluminium alloy 7075 is researched. The critical damage value is equal to 2.13 from the simulation based on the comparison between the experimental and simulation results of the clinching process investigation regarding fracture initiation as shown below in Fig. 7 .

\section{Investigation methods}

The clinching tools are comprised of a stepped punch, a spring loaded stripper tip, a die anvil, surrounding die blades, an elastomer ring and a surrounded die cage. The open multiple-part die features a built-in die anvil that surrounds an elastomer ring and three die blades. FEA was aimed at optimising the clinching process with the minimisation of the fracture risk assessed by the maximum damage variable $C_{\max }$. Variations of the initial tool geometry were carried out for this purpose (Fig. 6). The optimisation phase was firstly started with a variation of the die blade stiffness $\mathrm{k}$ by the use of an external spring force. The basis was the reference parameter of $10 \mathrm{~N} / \mathrm{mm}$ from the model validation phase (Table 1). In the following step the optimisation deals with the variation of the punch diameter based on the stiffness variants I-0, III-0, V-0 (Table 2 and Table 3).

The built up model of the clinching process was a 2 dimensional model. To simulate the clinching process with the open die, a combined friction model was chosen. Therefore the

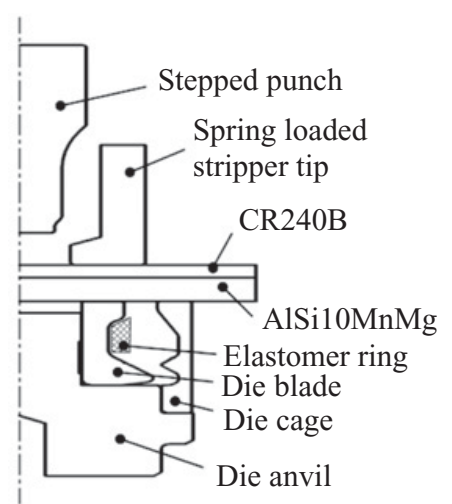

Figure 6. Initial tool geometry $\left(X^{\mathrm{ini}}\right)$. 
coulomb friction coefficient between the steel sheet CR240BH and the tools was set to $\mu=0.2$ and the plastic shear friction coefficient was set to $m=0.4$. Between the die-cast aluminium AlSi10MnMg and the die the parameters were selected to $\mu=0.05$ and $m=0.1$. The velocity of the stepped punch was set to $10 \mathrm{~mm} / \mathrm{s}$. Furthermore, a stripper spring was integrated in the stripper tip with a spring rate of $\mathrm{c}=580 \mathrm{~N} / \mathrm{mm}$ and a preloaded stripper force of $5 \mathrm{kN}$ according to the reference. The punch stroke was defined in the forming control, ensuring that the gap between the punch and the die was $0.91 \mathrm{~mm}$ at the end of the clinching process. The gap value was generated by experimental bottom thickness of the clinched joint.

\section{Results and discussion}

The first simulation phase was, based on the comparison between the experimental and simulation results of the clinching process with an open die, validated. As shown in Fig. 7, the simulation presents a good agreement in comparison to the experiment. The error rates of the joint parameters between the experiment and the simulation are less than $7 \%$. Furthermore, the stepped punch forming force $F_{\mathrm{p}}^{\max }=32.5 \mathrm{kN}$ is acquired in the simulation.

The results for the variation of the die blade stiffness by an external spring force and the

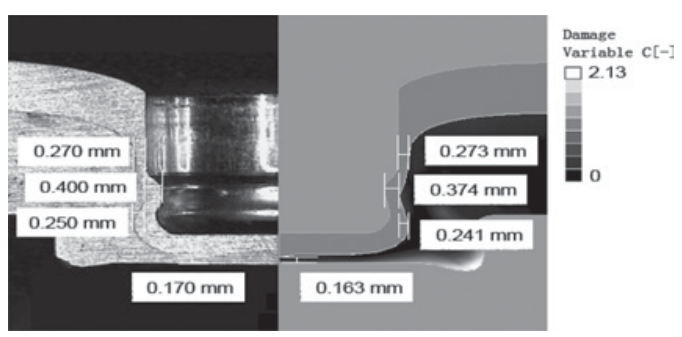

Figure 7. Geometry parameters of the clinch point in the experiment (left) and simulation (right).
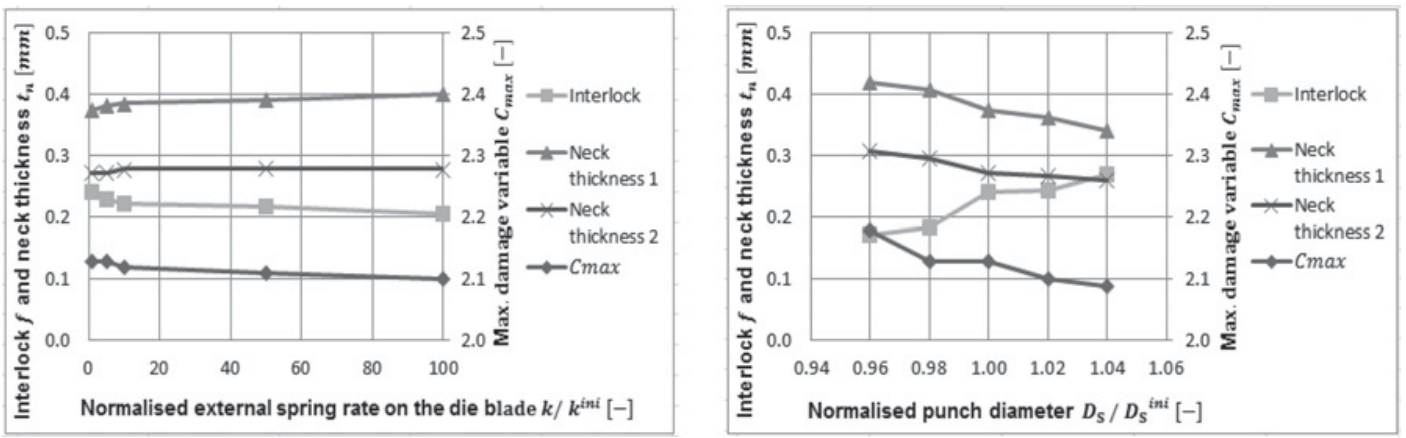

Figure 8. Simulation results of the variants I-0 to V-0 from Table 1 (left); variants I-1 to I-5 from Table 2 (right).

stepped punch diameter are shown in Figs. 8 and 9. It can be seen that the variation of the die blade stiffness affects the clinch joint parameters interlock and neck thickness as well as the maximal damage variable. With the use of an external spring force and the resulting increasing die blade stiffness $k$, the maximal damage variable $C_{\max }$ declines slightly while the interlock $f$ decreases and the neck thickness $t_{\mathrm{n} 1}$ increases. The value of the neck thickness $t_{\mathrm{n} 2}$ remains almost on an equal level. With an increasing step punch diameter $D_{\mathrm{s}}$ based on the variation $\mathrm{V}-0$, the maximal damage variable $C_{\text {max }}$ decreases with a minimisation from 2.13 to 2.02 . The interlock $f$ reveals a trend to apparent increase while the neck thickness $t_{\mathrm{n} 1}$ and the neck thickness $t_{\mathrm{n} 2}$ decrease. Therefore, the design tool variant V-5 was regarded as the optimum based on the minimal damage variable $C_{\max }$ and acceptable clinch joint parameters. 

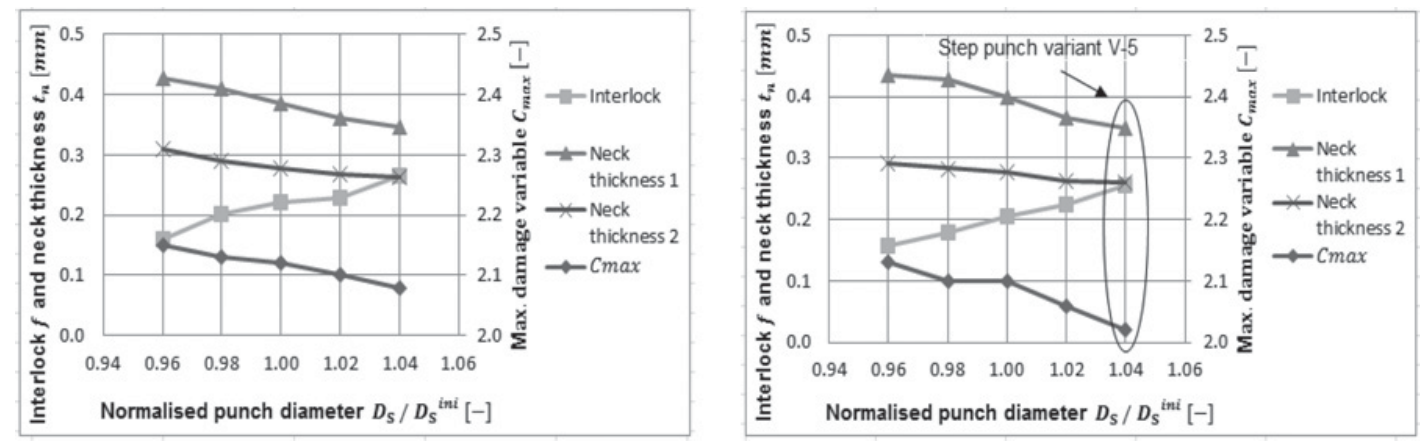

Figure 9. Simulation results of the variants III-1 to III-5 from Table 2 (left); variants V-1 to V-5 from Table 3 (right).

\section{Summary and outlook}

The objective of the present study was the FEA-based optimisation of the tool design of a clinching process with an open multiple-part die aimed at damage minimisation in CR240BHAlSi10MnMg joints. The numerical simulation of the material flow and the friction conditions were carried out during the clinching process with the open multiple-part die based on the comparison between the simulated clinch point geometry and punch force with the corresponding experimental data. The Oyane damage criterion was applied to describe the damage behaviour of the die-cast aluminium alloy AlSi10MnMg. The criterion parameters were referred from the literature for a similar aluminium alloy while the critical value of the damage variable was obtained based on the comparison between the experimental and numerical results of the studied clinching process. After the validation of the simulation model, the variation of the die blade spring rate by an external spring force was investigated as well as the variations of the stepped punch diameter. The clinching tools were improved to minimise the fracture risk on the die-cast aluminium alloy AlSi10MnMg. The tool design variant with an external spring rate of $1000 \mathrm{~N} / \mathrm{mm}$ and a stepped punch diameter of $5.6 \mathrm{~mm}$ was the optimum variant of the carried out investigations. A minimisation of the maximum damage variable from 2.13 to 2.02 with a slight decrease of the neck thickness was achieved. The optimised clinching tool designs with an open multiple part die were proposed in the study. The variations of the die anvil height and the stepped punch stroke might further minimise the fracture risk. Therefore, more FEA-based numerical processes must be carried out. In accordance with the numerical optimisation the optimised clinching tools need to investigate experimentally. The results of the experiments verify whether the found out minimisation of the maximal damage variable is enough to eliminate the fracture in die-cast aluminium alloy AlSi10MnMg. The experimental investigations with the optimised tools are in preparation.

The project 01/211/16819 N "Clinching of die-cast components" of the European Research Association for Sheet Metal Working (EFB), Hannover, is financially supported through the German Federation of Industrial Research Associations (AiF), Cologne, by the German Federal Ministry of Economic Affairs and Energy (BMWi), Berlin. The authors thank the sponsor BMWi, the project coordinators AIF and EFB as well as the members of the industrial project consortium. The support of Volkswagen AG for the provided die-cast material and BTM Blechverbindungstechnik $\mathrm{GmbH}$ for the preliminary experimental clinching process investigations is especially appreciated.

\section{References}

[1] N.N, DIN 8593: Fertigungsverfahren (2003) 


\section{ICNFT 2015}

[2] O. Hahn, U. Klemens, Fügen durch Umformen, Nieten und Durchsetzfügen (1996)

[3] Y. Abe, K. Mori, T. Kato: Joining of high strength steel and aluminium alloy sheets by mechanical clinching with dies for control of metal flow, J. Mat. Proc. Tech. 212, 884-889 (2012)

[4] H. Liebig, Press joining of especially coated steel and aluminium sheets, Advanced Technology of plasticity (1987)

[5] Y. Tan, Process Monitoring Method with Window Technique for Clinch Joining, ISIJ, 45, 723 (2005)

[6] B.-A. Behrens, A. Bouguecha, M. Vucetic, S. Hübner, D. Yilkiran, Y.L. Jin, I. Peshekhodov: FEA-based optimisation of a clinching process with a closed single-part die aimed at damage minimisation in CR240BH-AlSilOMnMg joints, Proceedings of the $18^{\text {th }}$ International ESAFORM conference on Material Forming 2015 in Key engineering materials (2015)

[7] D.-C. Chen, C.-S. You, F.-Y. Gao, Analysis and experiment of 7075 aluminium alloy tensile test, P. E. 81, 1252-1258 (2014) 